Portland State University

PDXScholar

2-2-1987

\title{
Bronze Casting by the Lost Wax Method Employing Mixed Media
}

Donna M. Pickett

Portland State University

Follow this and additional works at: https://pdxscholar.library.pdx.edu/open_access_etds

Part of the Art Practice Commons, and the Sculpture Commons Let us know how access to this document benefits you.

Recommended Citation

Pickett, Donna M., "Bronze Casting by the Lost Wax Method Employing Mixed Media" (1987).

Dissertations and Theses. Paper 3465.

https://doi.org/10.15760/etd.5349

This Thesis is brought to you for free and open access. It has been accepted for inclusion in Dissertations and Theses by an authorized administrator of PDXScholar. Please contact us if we can make this document more accessible: pdxscholar@pdx.edu. 
BRONZE CASTING BY THE LOST WAX

METHOD EMPLOYING MIXED MEDIA

by

DONNA M. PICKETT

A Thesis Report Submitted in Partial Fulfillment of the Requirements for the Degree of

\author{
MASTER OF FINE ARTS \\ in
}

SCULPTURE

Portland State University, 1987 
TO THE DEPARTMENT OF ART AND ARCHITECTURE:

The Members of the Thes is Committee Approve the Thesis and Report of Donna M. Pickett presented February 2, 1987.

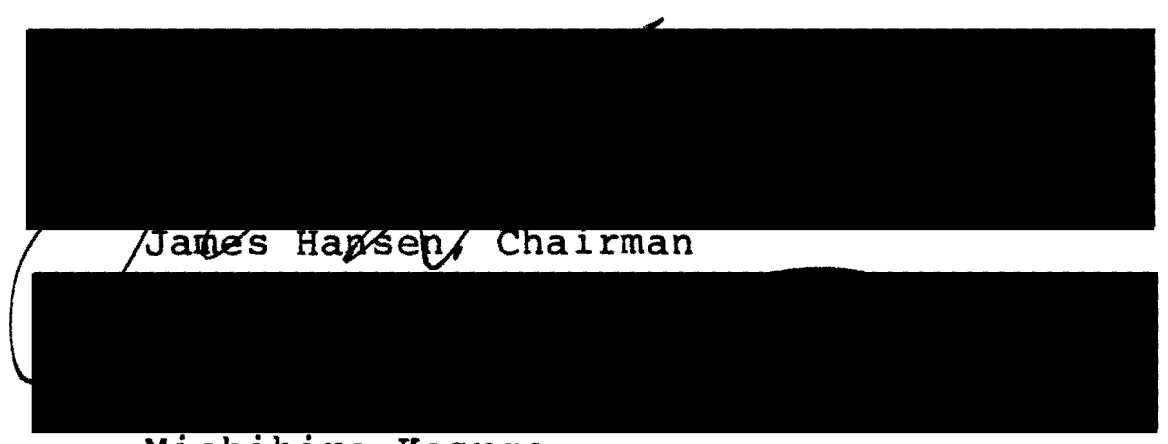

Michihiro Kosuge

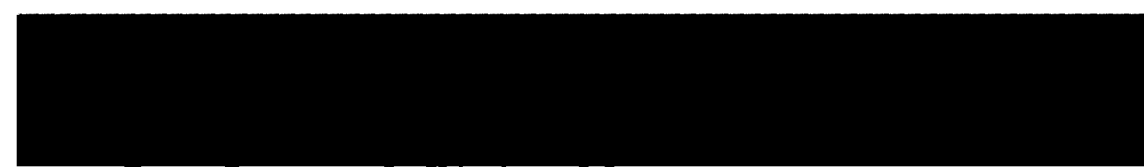

Dr. Leonard Kimbrell

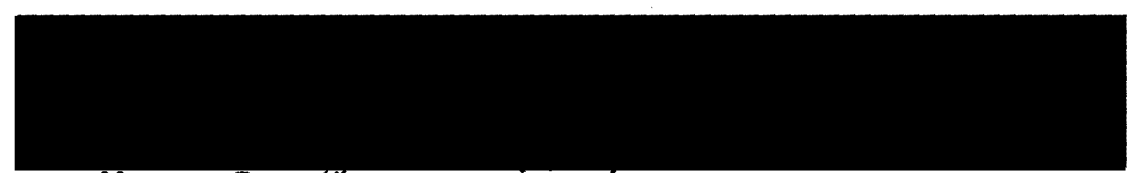

Mary Consfans

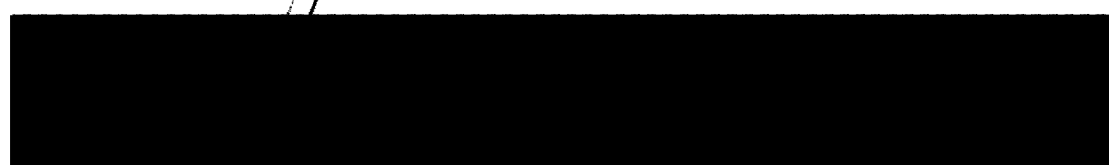

Robert Tuttle

\section{APPROVED :}

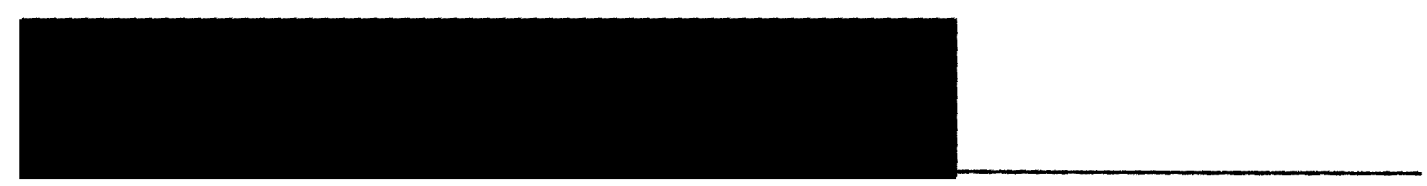

Robert Kasal, Head, Department of Art and Architecture 
TABLE OF CONTENTS

PAGE

LIST OF FIGURES . . . . . . . . . . . . . . . . . I iv

INTRODUCTION. . . . . . . . . . . . . . . . . . . 1

IMPERSONAL DESTRUCTION FROM THE AIR . . . . . . . . 5

THE A-BOMB DOME . . . . . . . . . . . . . . . . . . . 8

THE SURVIVORS . . . . . . . . . . . . . . . 15

PHOENIX .................... . . . 18

CONCLUSION. . . . . . . . . . . . . . . . . 20 


\section{LIST OF FIGURES}

FIGURE

PAGE

1. Impersonal Destruction From the Air . . . . . . 3

2. Impersonal Destruction From the Air . . . . . . 4

3. The A-Bomb Dome . . . . . . . . . . . . 6

4. The A-Bomb Dome . . . . . . . . . . . . . 7

5. The Survivors . . . . . . . . . . . . 13

6. The Survivors . . . . . . . . . . . . . . 14

7. Phoenix • . . . . . • . . • • • • . 16

8. Phoenix • . . . . . . . . . . . . . . . 17 


\section{INTRODUCTION}

Two years ago, when I started the MFA program, I had three concerns in my work. First, I wanted to work with figures in a realistic way, breaking down or fragmenting the surface of the figures while keeping the form intact. Second, I wanted to bring attention to the interior of a subject. Finally, I required both the interior and the exterior of the figure to bear evidence of the emotional condition which I sought to expose.

Initially, my approach to these concerns was to conduct a series of small experiments, the cumulative result of which would satisfy my objectives.

It happened though that in the summer of 1985 I became interested in the fortieth anniversary of the bombing of Hiroshima. Newspapers, television and magazines were certainly giving much attention to the event. I began consciously to take time to absorb information pertaining to the Hiroshima experience. Before long I realized that I must use this theme in my work. In fact, this subject could embody all of my sculptural concerns. As I watched the story behind August 6,1945 , unfold, I felt committed to investigate the emotional ramifications of the "victim 
phenomenon". Familiarity with pain and suffering is, unfortunately, universal.

I formulated a plan to deal with the events of the bombing as well as convey their emotional impact on an audience. I chose to use a narrative made up of four separate scenes in cast bronze, cast aluminum, and steel. Each scene would be composed of two parts, a victim and a location in time. One live model was used for all of the heads. In this, I was lucky enough to find a young Japanese woman with features perfectly suited to my purposes, especially her lips, which I felt were vital to the expressive quality of the head.

The total work is entitled Hiroshima'85-Nuclear Summer. Each of the scenes is subtitled. 


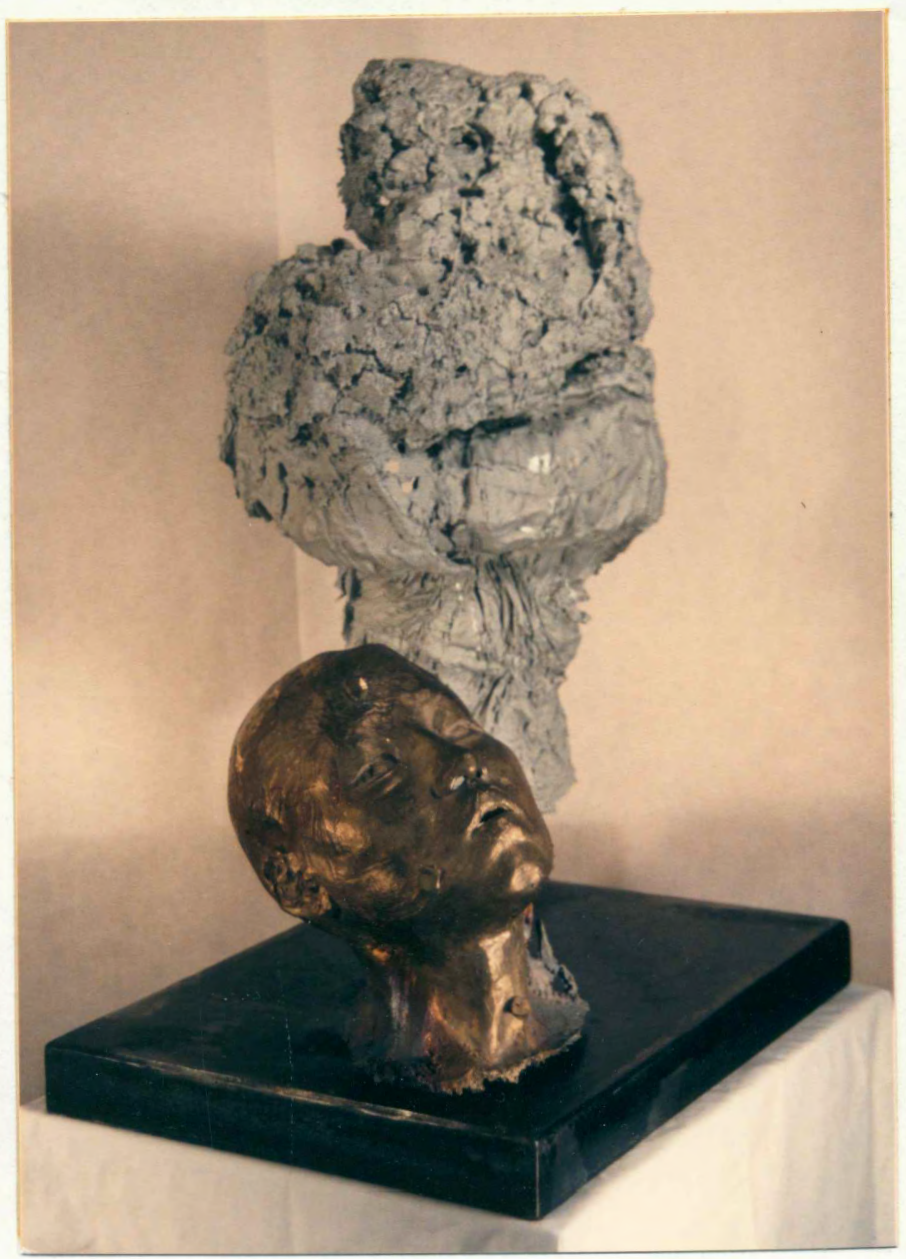

Figure 1. Impersonal Destruction From the Air 


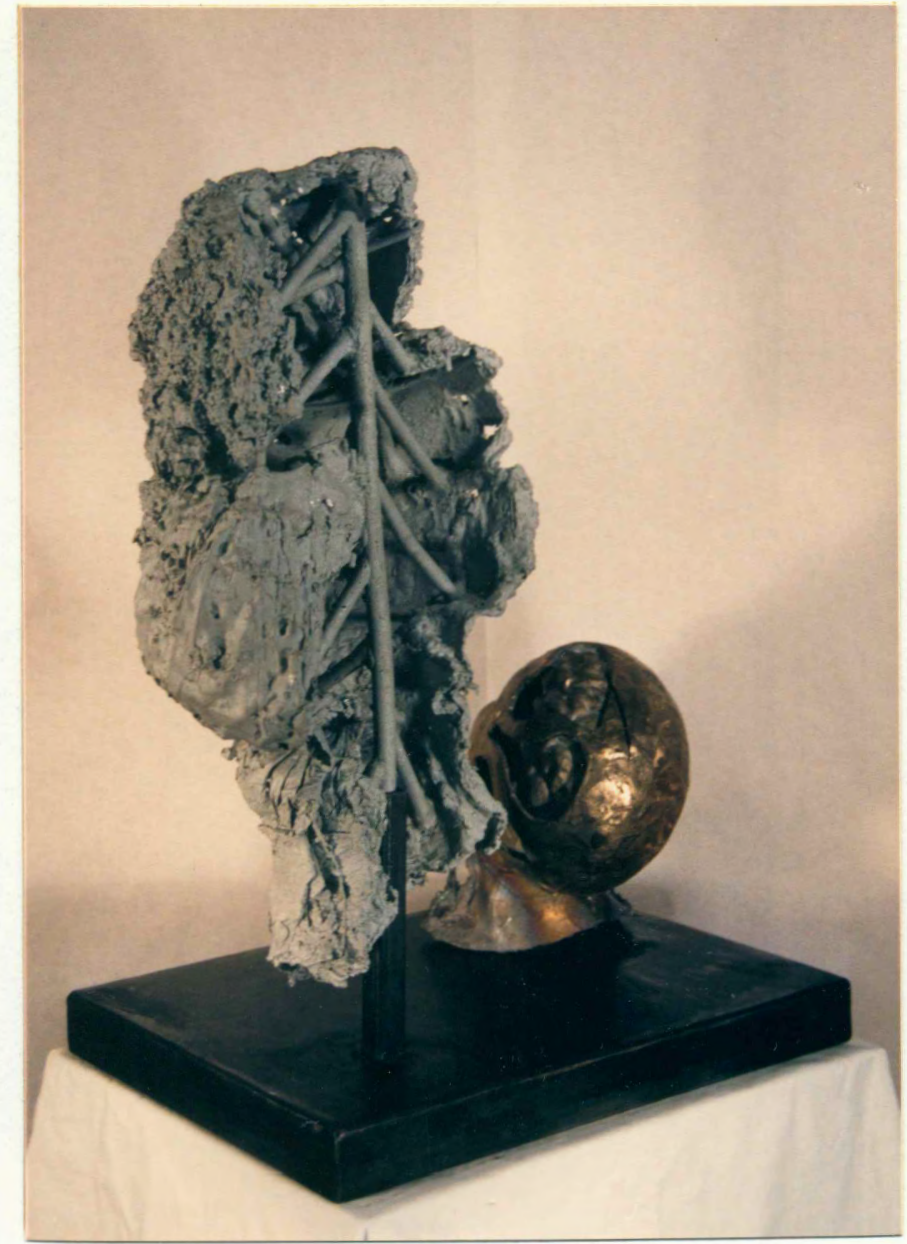

Figure 2. Impersonal Destruction From the Air 
IMPERSONAL DESTRUCTION FROM THE AIR

In Impersonal Destruction From the Air I wanted to tell two stories, the story of the people and the story of the event in the instant of its occurrence. In this, I concentrated on the victims, those who died instantaneously at the time of the blast. The exposure of the brain and the off-balance attitude of the head are meant to convey the moment of death. To record my own attitude I inscribed words and phrases on the skull. The associated mushroom cloud was the most difficult part of the total work. I felt that this constituent fact could not be left out. It was certainly paramount to the narrative and began the story of the events. The question was how was I to cast an explosion in bronze? It was a difficult problem and I struggled with it, yet I saw no reason to give it up. I had dipped a large plastic bag in wax and added styrofoam billows. I had trouble however with the idea that bronze air seems heavy, yet air should appear to be light and rising. When I considered casting the cloud in aluminum these troubles seemed to disappear. Then, not only was the piece physically light, but the material was the right base color for a gray cloud. 


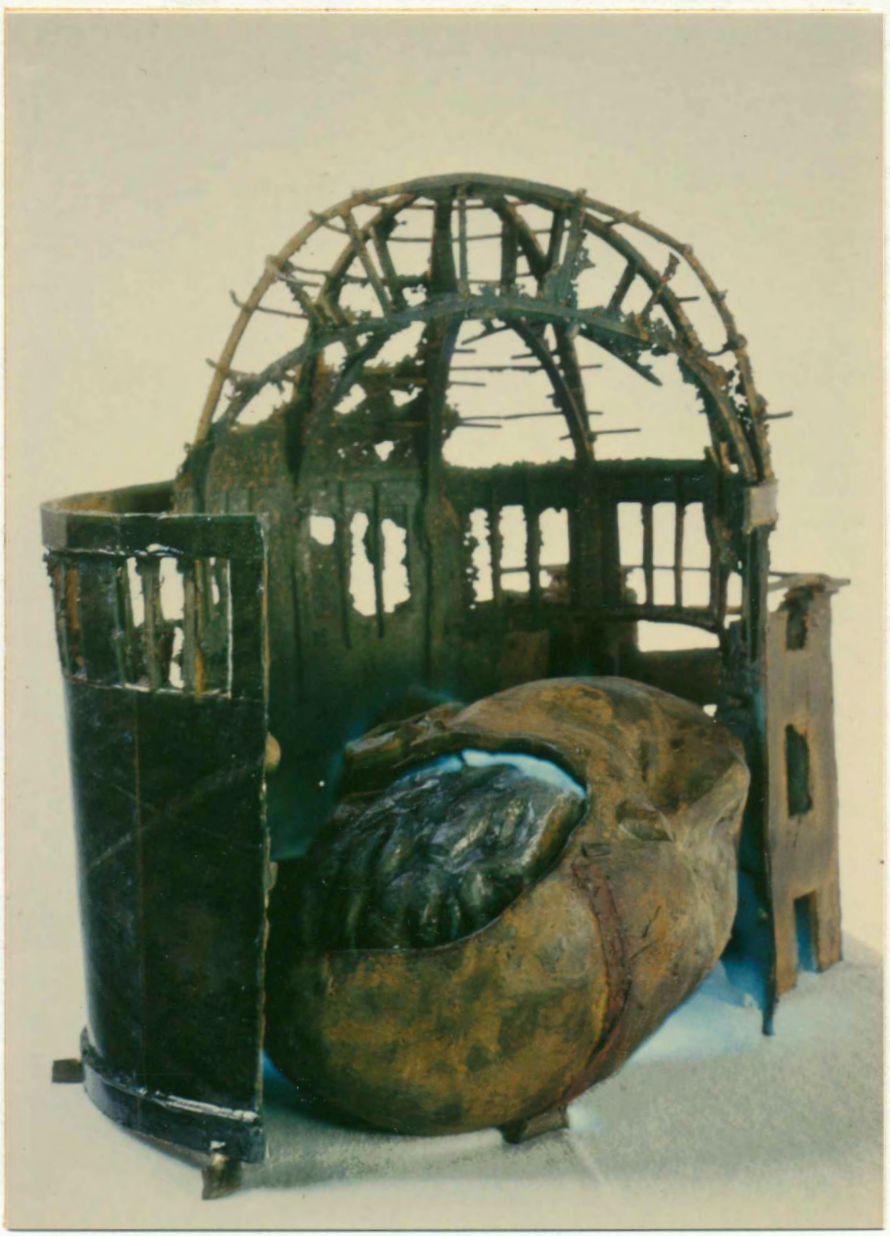

Figure 3. The A-Bomb Dome 


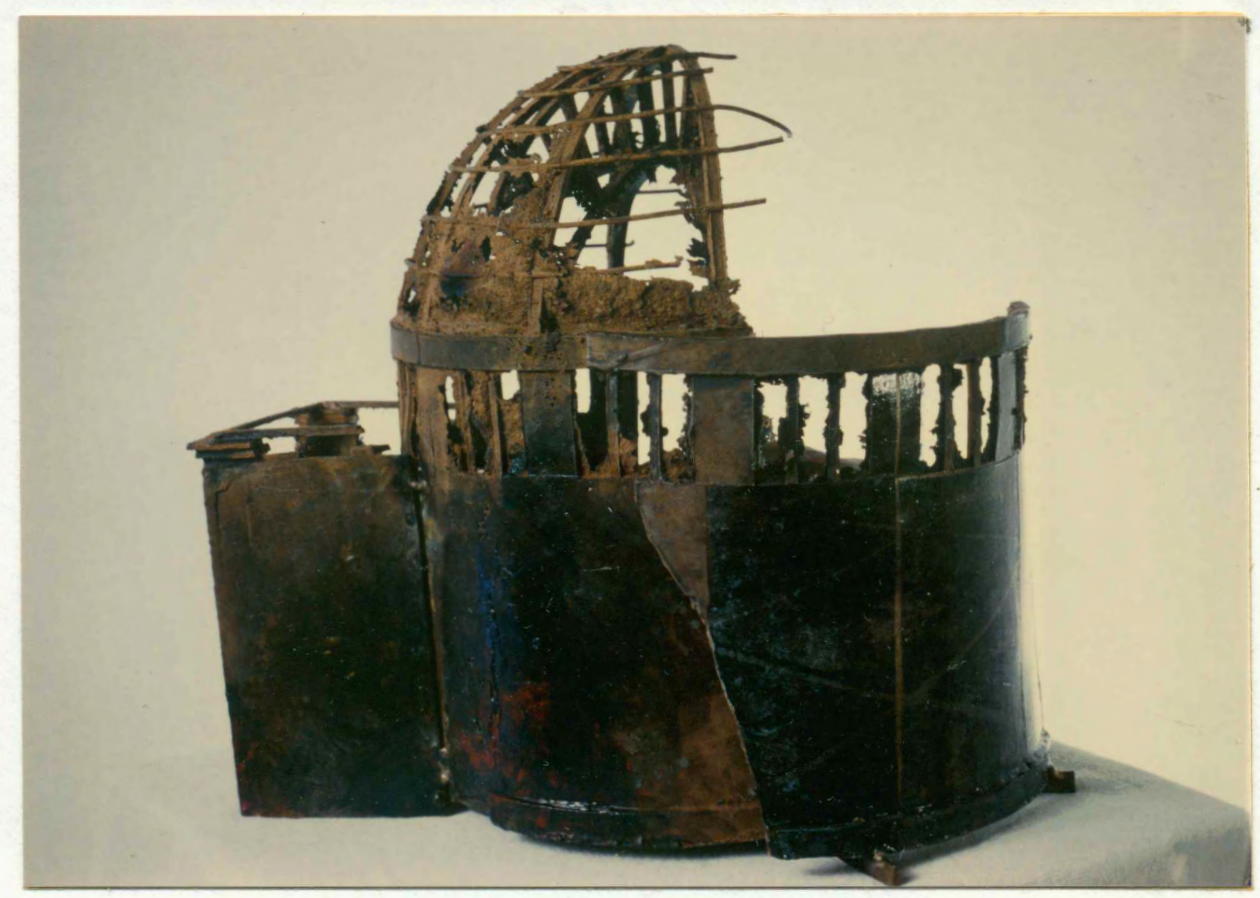

Figure 4. The A-Bomb Dome 
THE A-BOMB DOME

The second piece, the A-Bomb Dome, consists of a representation of the "A-Bomb Dome", stark survivor of the bomb blast in Hiroshima, and another head taken from the original mold. The form of the head was not reworked or altered in any significant way. I simply removed a large area from the right side of the skull. I then carved the perimeter of this opening to match the edges of another brain. At this point, I tried to avoid letting the actual edge of this cut become an issue. I did not want to be detained by technical processes or the finish of any area but wanted rather to complete each task to fulfill my idea of the immediacy of the event. Later I would assess the visual result. The criterion I held for this hole was that the two edges should coincide on two different planes, approximately one quarter inch apart in depth. This would leave a crack which could emit rays from a light which would be placed inside the head, but which would be too small to provide a view to the interior of the skull. The light was meant to signify a survivor. I wanted the viewer to become aware that something in this graphic scene of destruction was still alive, something that would be personified as the survivor in the third piece and as the hope of future 
survival in the last piece. Here the only hint of that survival is the light.

There were certain technical problems to be dealt with at this point. The bronze had to be enticed to flow into the brain, yet the brain had to appear to be in no way connected to the skull or neck. I overcame this problem by careful placement of the spruing structure on the exterior of the piece and by providing adequate wax routes from the head to the brain in the interior. Both the head and the brain were made of very thin wax, slightly over one-eighth inch thick. I like to take risks with my castings and could afford to lose this piece since I had two good molds to fall back on in case of failure.

The western style A-Bomb Dome is not an image one might expect among the carefully chosen Japanese motifs in the whole of the piece. This building, which was originally an exhibition hall, worked well visually with the other elements of the work that I chose to include with the head in this second piece. Thus far I used chiefly spherical elements: the two heads, the mushroom cloud and the dome. Thus I sought to achieve visual unity in the total work. The "A-Bomb Dome," located at the epicenter of the bombing, remained standing while the rest of the city was flattened in every direction by the holocaust of August 6 , 1945. This ruin has been preserved as the center of the present Peace Park. I felt that this monument qualified as 
representative of the whole city of Hiroshima in the second part of my narrative, and afforded me the opportunity to deal with the city in a very literal way. With the introduction of the dome I wanted to accomplish two disparate things: one, to make it realistic enough to be easily recognizable and therefore site-specific; and as a challenge to me from a compositional and technical viewpoint.

The success that I had had in wax work I felt would be easy to translate into metal. Working with wax was similar to working with welding. I cut out wax elements, much as one would cut metal, and welded them together. It seemed that I should give myself the opportunity for spontaneity and freedom in metal that I had found in working with wax. The dome was made in wax with all of the "parts" which I felt were necessary for identification and character. I used several photographs of the building as I worked on the wax. When the building was completed, I cut it up and cast the parts separately. I could then play with the parts of the building and the head to decide on the final form of their relationship. Once I had made a decision, I welded the building together. The result was that the building became another disembodied, floating form, as I had planned. The walls were layered because I wanted one to see through the windows. That also made a perfect opening for the head, permitting it to be partially hidden inside the building. 
Hiding the head accomplished two things. It gave variety to repeated use of the head, and, more importantly, it gave the most advantageous angle for presentation of the partially exposed brain of the head. In the first piece I emphasized destruction. In this piece, by implying the escape of a few with the blue light, I hinted at survival. The light which seeps out between the skull and the brain is intended to show that someone was still alive.

In this piece I was finding more freedom with the metal and, with a little investigation, also found more freedom with my color. I intended the patina to reinforce the just-bombed look that I had already achieved in the form. I tried to bring out as much red as I could, and thought I had accomplished my goal. To my dismay, within two days all of the red had turned to black.

I had never painted with acrylics before so this seemed a good time to start. I began to add red to the "reflection" side of the building where I had lost the color earlier. I had prepared the independent wall by beating the surface with a hammer to a smooth finish. During this work I got a lot of hand oil on this area and that is what gives it rich color. I then attached to this wall a transparent magazine photograph of the blasted city. I wanted to incorporate images of as much of the destroyed surroundings as I could. The reflections of the blast, and then the ruined streets, worked to provide these images and also to 
provide a time sequence. Parts of the head and brain are also painted with acrylic paint.

I used myself as a standard height for a viewer, 5' 6". A view from slightly above the head gives one the opportunity to see the network of the dome yet look down on the fallen head. The stands, painted with a dark neutral enamel, reflect the blue light to advantage. 


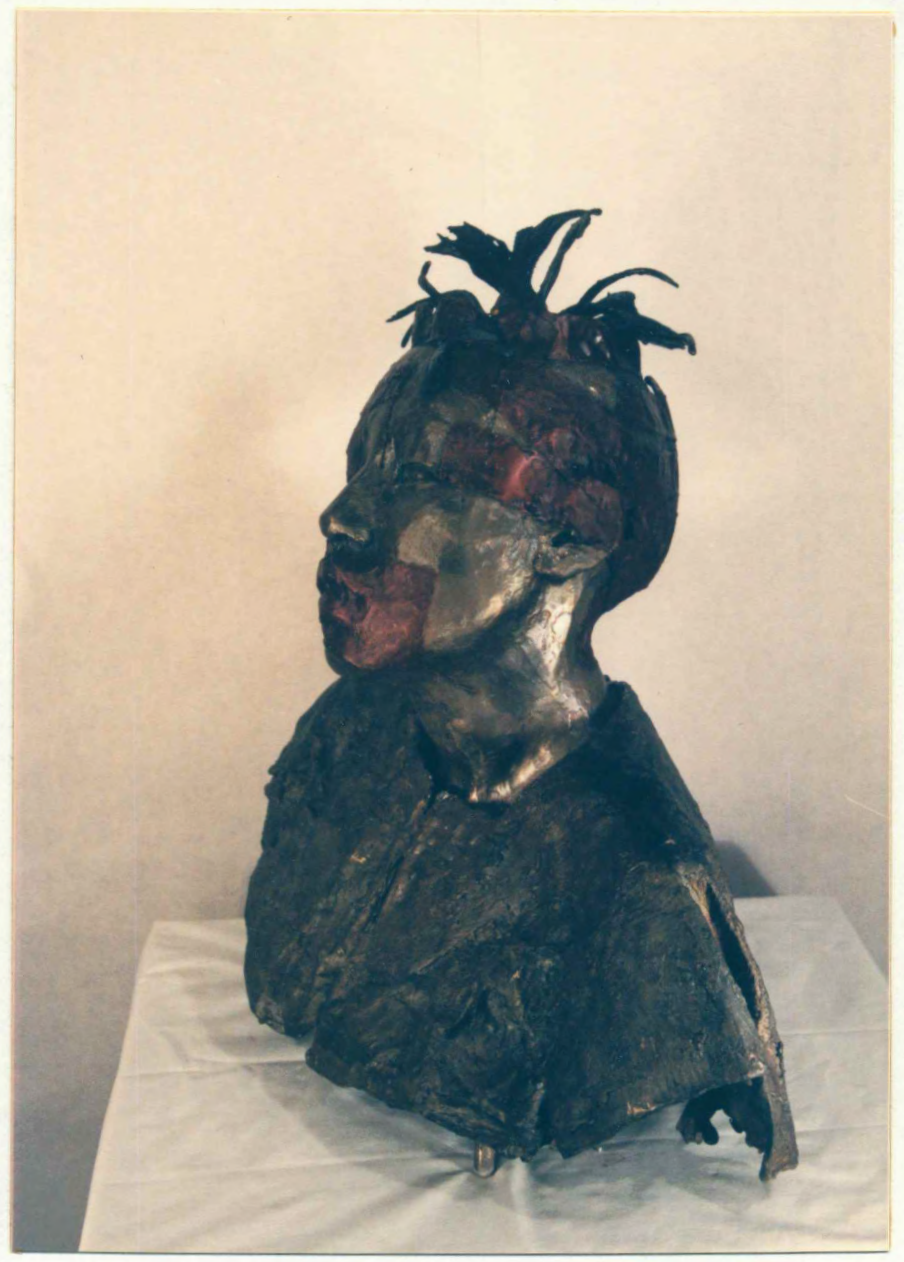

Figure 5. The Survivors 


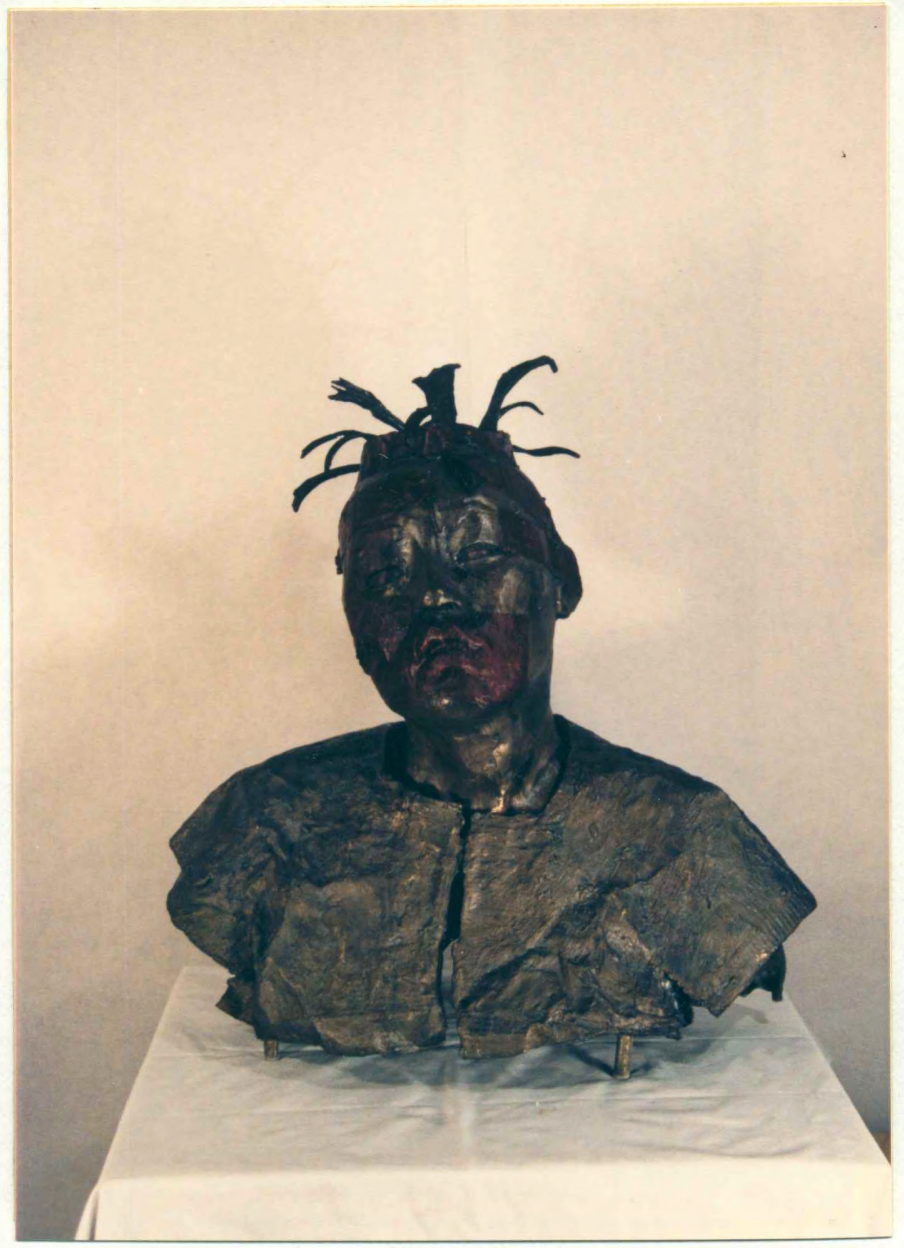

Figure 6. The Survivors 
THE SURVIVORS

I described earlier the importance attached to the lips of the figures. The head that represents the survivors was the piece in which the lips could be used most expressively. In it there was a cry for help stifled by the bandages. I felt sympathetic with the plight of the burned survivors then and I feel it now.

This piece became progressively more abstract as I worked on it. The literal elements were these: human hair, cloth bandages, a real hospital shirt, in fact everything but the real victim. Radiation sickness includes a stage during which the hair falls out in patches. Victims were heavily bandaged for burns. Everyone was either dying or recovering in makeshift hospitals, hence the hospital shift. Yet, the placement of the hair and bandages, and the obvious lack of a body inside the garment were calculated, designed to bring about an interplay of subject versus abstraction in both a sculptural and visual sense.

The bandages and hair were painted with an application of oil stick thinned with linseed oil. This made a very clear transparency of color which revealed the character of the bronze surface texture underneath. 


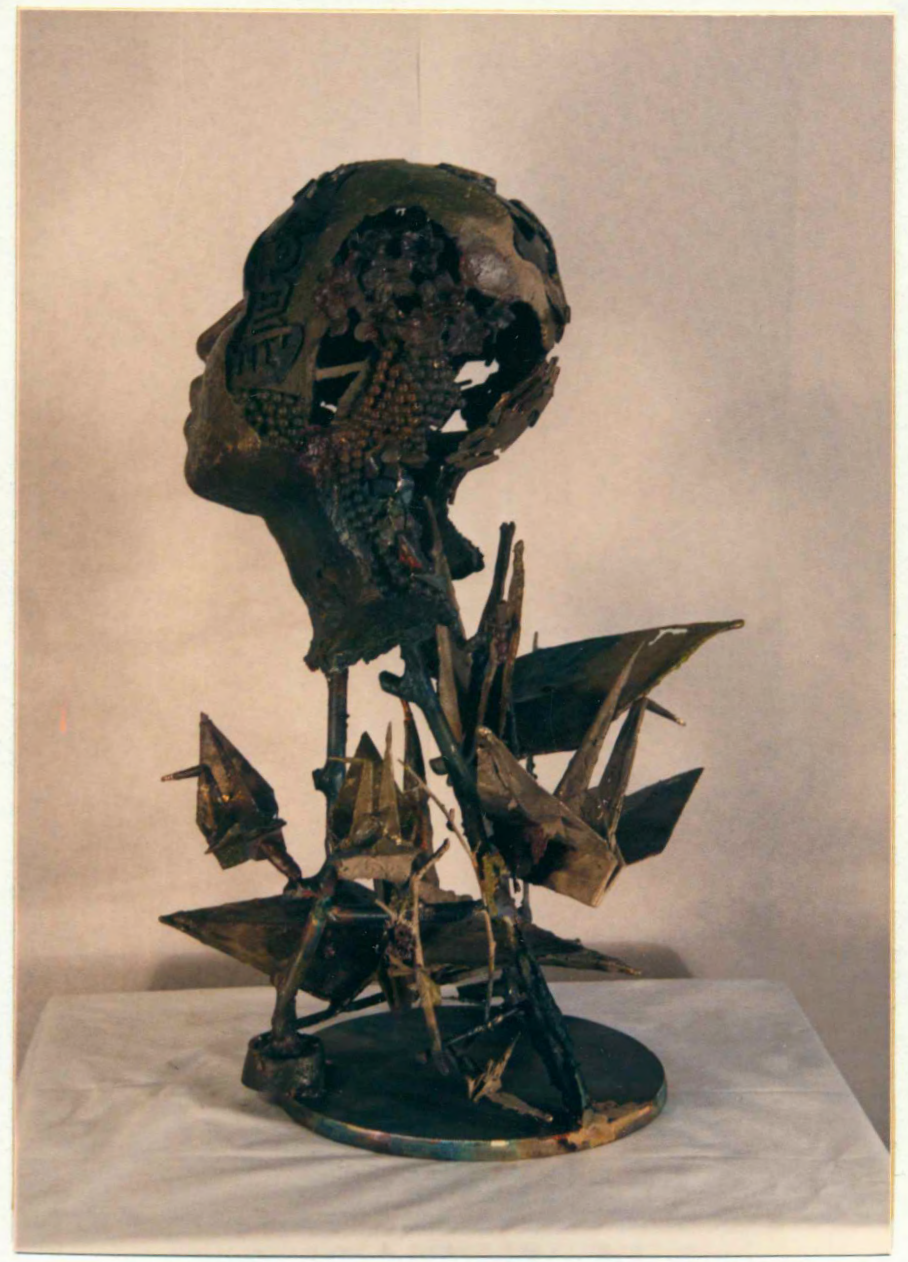

Figure 7. Phoenix 


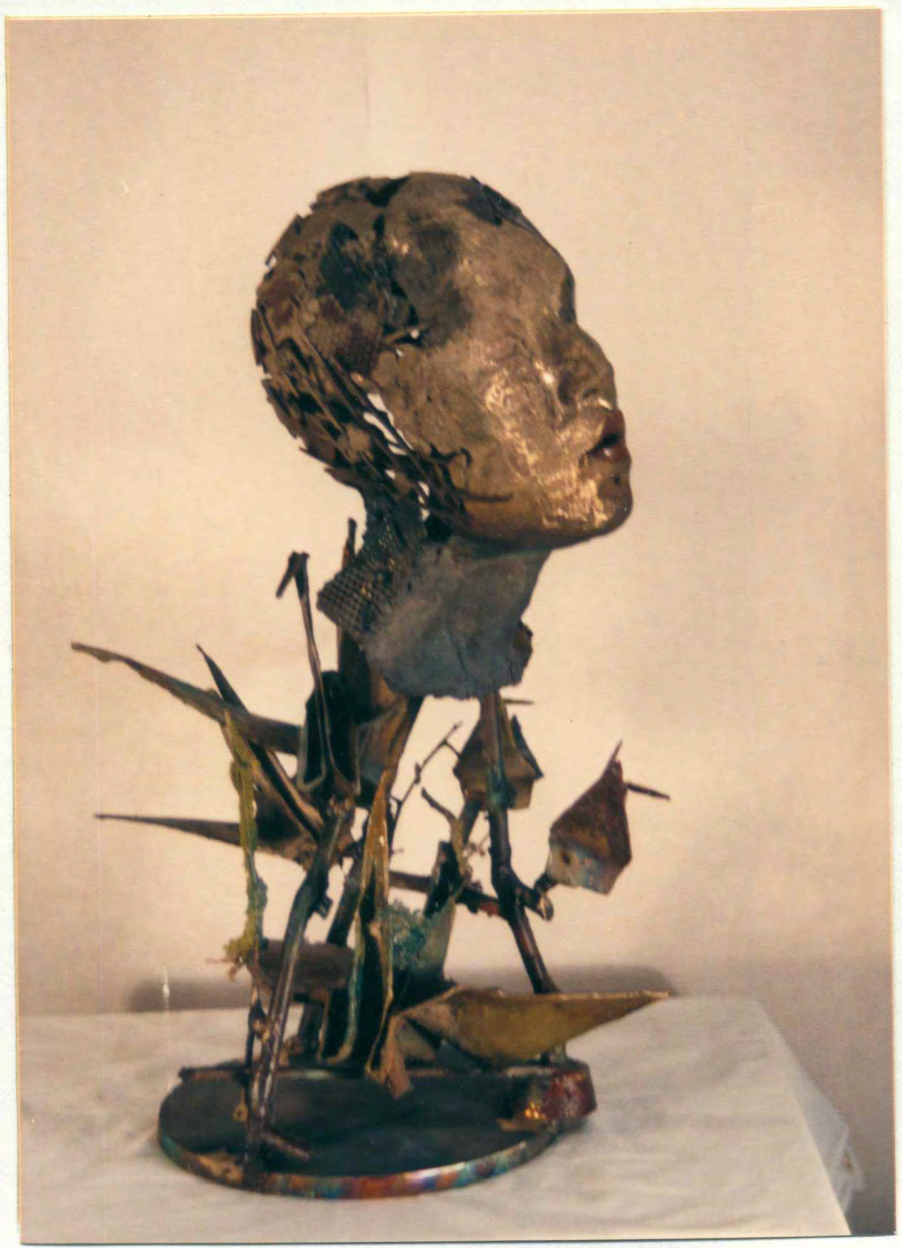

Figure 8. Phoenix 
PHOENIX

I was impressed by the determination of the people to rebuild Hiroshima as a monument to peace. The epicenter of the blast remained the core of the city, with the Peace Park as its focus. This positive attitude and the rebirth of the city provided my motivation in the last piece. I wanted the viewer to feel hope. I meant this piece to be so attractive that the graphic violence of the first three scenes would be relieved. Every element in the head was chosen for pleasant associations. The flowers were placed in the position that the brain occupied in the first two heads.

Paper cranes and the cherry branches and blossoms are motifs specific to events of meaning to the Japanese people. These were also real objects that had been burnt out and then cast. The Japanese characters on the forehead of the figure mean Phoenix, the bird that rises from the ashes. I built the head from the inside of a plaster mold and built the spruing structure into the interior in process. This allowed me to produce a casting with no finishing work on the surface and consequently no tool marks to cover up. Each part was cast separately and then assembled by welding as I had done in the second piece. 
I wanted the textures to be very visible so I chose to paint some of the surfaces with an acrylic wash and left the remainder in bare bronze. 


\section{CONCLUS ION}

The finished ensemble is successful for me. The strong motivation behind it is essential in my work. I started with a thought-out plan and, even though the plan evolved and the project took the better part of two years, I never encountered any real trouble nor did I ever lose interest. I felt free to take a stand on some important personal preferences. I feel strongly about the finishing processes, the use of paint on metal, and the employment of chance. My reward from this experience has been to gain faith in my judgments. Therefore $I$ have the desire to continue my work. 